\title{
Experiência da Psicologia na Estratégia Saúde da Família
}

\author{
Experience Of Psychology \\ In The Family Health Strategy
}

Experiencia De La Psicología En La Estrategia Salud De La Familia

Angélica Paula

Neumann,

Cassandra Cardoso \&

Silvana de Oliveira

Universidade Regional do Alto Uruguai e das Missões - Campus de Erechim
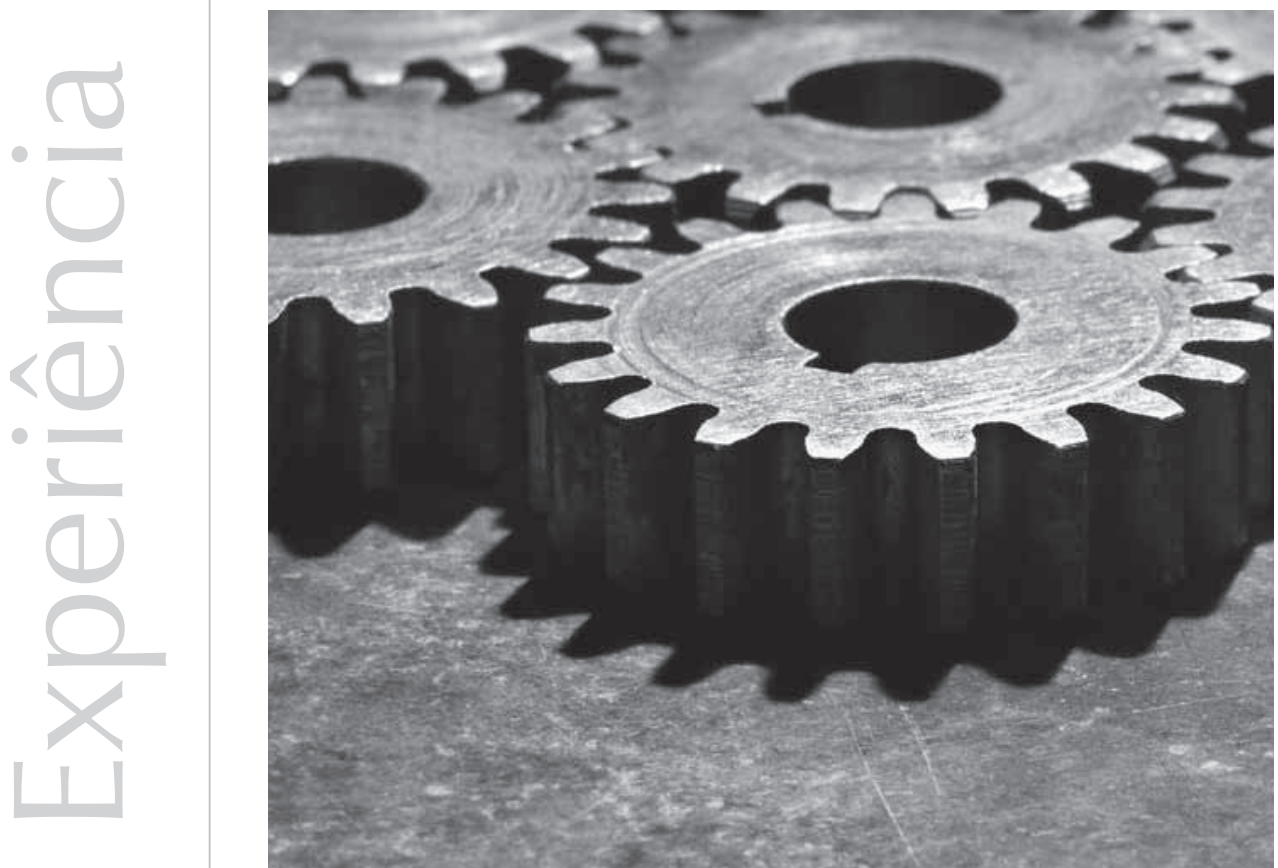
Resumo: Este artigo apresenta os resultados de um projeto de extensão universitária intitulado $A$ equipe de saúde na comunidade, o qual, no período de agosto de 2008 a julho de 2009, viabilizou um trabalho de assessoria a 15 agentes comunitárias de saúde de 3 equipes da Estratégia Saúde da Família. Os objetivos do projeto foram abrir um espaço de reflexão sobre o cotidiano de trabalho das profissionais e possibilitar a construção coletiva de saberes sobre sua prática. As atividades foram realizadas por meio de grupos quinzenais de reflexão, efetuados na unidade básica de saúde do bairro em que as participantes trabalham. Os resultados apontam um aperfeiçoamento pessoal e profissional das participantes, que relataram transpor as reflexões efetuadas no grupo para os desafios de seu dia a dia. Elas também apontaram um aperfeiçoamento em relação a seu próprio grupo de agentes comunitárias, retomando uma percepção, que já haviam possuído anteriormente, de si mesmas como uma equipe em que há auxílio mútuo e troca de experiências. A execução desse projeto denota a possibilidade de potencializar o trabalho dos agentes comunitários de saúde através do investimento em seus recursos pessoais e relacionais, o que pode ser aprimorado ainda mais se associado ao trabalho da equipe de saúde.

Palavras-chave: Saúde da família. Pessoal técnico de saúde. Serviços de saúde pública. Discussão em grupo

\begin{abstract}
This article presents the results of a university extension project entitled "The health team in the community", which from August 2008 to July 2009 enabled an advisory work to fifteen community health agents from three teams of the Family Health Strategy. The goals of the project were open a space of reflection about the daily work of the professionals and enable the joint construction of knowledge about their practice. The activities were conducted through biweekly reflection groups, held in the basic health unit of the neighborhood in which the participants work. The results show a personal and professional development of the participants, who reported the crossing of the reflections made in the group for the challenges of their daily work. They also showed an improvement over their own group of community health agents, resuming a perception, which they had previously possessed, of themselves as a team that can assist each other and exchange experiences. The work shows the possibility of enhancing the work of the community health agents by investing in their personal and relational resources, which can be further enhanced if associated with the work of the health team.
\end{abstract}

Keywords: Family health. Allied health personnel. Public health services. Group discussion.

Resumen: Este artículo presenta los resultados de un proyecto de extensión universitaria, intitulado "El equipo de salud en la comunidad", el cual, en el periodo de agosto de 2008 a julio de 2009, ha tornado viable un trabajo de asesoría a quince Agentes Comunitarias de Salud de tres equipos de la Estrategia Salud de la Familia. Los objetivos del proyecto han sido abrir un espacio de reflexión sobre el cotidiano de trabajo de las profesionales y posibilitar la construcción colectiva de saberes acerca de su práctica. Las actividades han sido llevadas a cabo por medio de grupos quincenales de reflexión, llevados a cabo en la Unidad Básica del barrio en el cual las participantes trabajan. Los resultados señalan un perfeccionamiento personal y profesional de las participantes, que han relatado transponer las reflexiones realizadas en el grupo para los desafíos de su día a día. Ellas también han señalado un perfeccionamiento en cuanto a su propio grupo de agentes comunitarias, retomando una percepción que ya habían poseído anteriormente de sí misma como un equipo en el que existe auxilio mutuo y cambio de experiencias. La ejecución de este proyecto denota la posibilidad de potenciar el trabajo de los agentes comunitarios de salud a través de la inversión en sus recursos personales y de relacionamientos, lo cual puede ser perfeccionado aún más si es asociado al trabajo del equipo de salud.

Palabras clave: Salud de la familia. Agentes comunitarios de salud. Servicios de salud pública. Grupo de dicussión.

Este artigo tem como objetivo apresentar os resultados do projeto de extensão universitária A equipe de saúde na comunidade, realizado pelo Curso de Psicologia da Universidade Regional Integrada do Alto Uruguai e das Missões - Campus de Erechim. O propósito desse projeto é viabilizar um serviço de assessoria a trabalhadores da Estratégia Saúde da Família, com o objetivo de abrir espaços de reflexão sobre o cotidiano de trabalho dos profissionais envolvidos e possibilitar a construção coletiva de saberes sobre a sua prática.

O projeto foi desenvolvido por duas docentes e uma aluna bolsista do Curso de Psicologia da Universidade, e o presente artigo irá apresentar os resultados obtidos durante o período de agosto de 2008 a julho de 2009, quando o trabalho foi realizado com 15 
agentes comunitárias de saúde de 3 equipes de saúde da família, todas vinculadas à mesma unidade básica de saúde. Nos anos 2005 a 2007, já houve outras três edições do projeto na UBS em questão, e as agentes de saúde participaram também da quinta edição, realizada entre agosto de 2009 e julho de 2010.

\section{Revisão da literatura}

A Saúde da Família é, atualmente, a estratégia prioritária do Governo Federal para o trabalho na saúde coletiva, visando à reorganização da atenção básica no País e tendo como pressuposto o acompanhamento domiciliar das famílias. A estratégia tem como objetivos principais a prevenção e a promoção da saúde da comunidade, e os profissionais são orientados a manter uma postura pró-ativa frente aos problemas de saúde e doença da população (Brasil, 2007; Lima \& Cockell, 2009).

A Estratégia Saúde da Família (ESF) é operacionalizada através de equipes multiprofissionais, compostas minimamente por médico, enfermeiro, técnicos de enfermagem e agentes comunitários de saúde (Brasil, 2007). O trabalho das equipes prevê a consolidação de vínculos entre os usuários do sistema e os profissionais que nele trabalham, o que requer o conhecimento da realidade da população, das organizações familiares e comunitárias e de suas características sociais, econômicas, culturais e epidemiológicas (Lima \& Cockell, 2009).

Com vistas à consolidação de vínculos, os agentes comunitários de saúde são os trabalhadores que se inserem nas equipes para atuar como mediadores da relação entre os usuários e os outros profissionais (Lima \& Cockell, 2009), sendo, por isso, considerados o elo entre a equipe e a população. Por serem emergentes da comunidade, são vistos como supostos conhecedores das formas cotidianas de viver, de significar a vida e de se comportar das famílias locais (Martines \& Chaves, 2007).

Também chamados de pedra angular do serviço de saúde, os agentes comunitários se integram às equipes multiprofissionais trazendo uma bagagem técnica deficitária relativa à sua prática, recebendo um treinamento limitado e direcionado a tarefas específicas (Bachilli, Scavassa, \& Spiri, 2008). Por outro lado, possuem como atribuições o exercício de atividades de prevenção de doenças e de promoção da saúde mediante ações domiciliares e comunitárias, desenvolvidas sob a orientação de um enfermeiro e em conformidade com as diretrizes do SUS (Brasil, 2007).

O agente comunitário é um dos personagens mais recentes do sistema de saúde pública brasileiro. Esse trabalhador deu seus primeiros passos na saúde coletiva em 1991 por meio do Programa de Agentes Comunitários de Saúde (PACS), e, em 1994, passou a fazer parte das equipes multiprofissionais que compunham o Programa Saúde da Família, tornando-se categoria profissional no ano 2002 (Martines \& Chaves, 2007).

Apesar de essa consolidação como categoria ter sido recente, as discussões existentes sobre as possíveis atribuições dos agentes de saúde despertaram o interesse da comunidade científica já no início de sua atividade profissional (Fernandes, 1992). Desde então, várias pesquisas têm surgido, abrindo espaço para uma busca ainda incipiente sobre o papel e a identidade desse trabalhador, investigando também as dificuldades envolvidas em sua prática e a sua potencialidade na operacionalização das ações em saúde (Bachilli, Scavassa, \& Spiri, 2008; Fortes \& Spinetti, 2004; Martines \& Chaves, 2007; Nunes, Trad, Almeida, Homem, \& Melo, 2002).

Furlan (2005) corrobora a percepção de que existem dificuldades concernentes à prática 
Em uma pesquisa realizada, Dalla Vecchia e Martins (2009) ressaltam ser necessária a existência de um espaço que possibilite a discussão

sobre o trabalho comunitário cotidiano e sobre os sentidos pessoais dados pelos profissionais da saúde às ações que executam. Em uma perspectiva similar, CamargoBorges e Cardoso (2005) destacam a necessidade de se criar ferramentas de intervenção mais apropriadas para o trabalho na saúde pública, sugerindo que a inserção da Psicologia na Saúde da Família pode trazer grandes contribuições. dos agentes comunitários. A autora questiona a relação entre o papel de identificador das problemáticas que esse profissional exerce e os conhecimentos que tem para perceber as situações vulneráveis da comunidade, e aponta ser necessária a capacitação dos agentes de saúde para o reconhecimento das demandas comunitárias que não chegam à unidade de saúde.

A autora supracitada descreve os resultados de um projeto de capacitação de agentes comunitários realizado em um Município do interior de São Paulo. Ela informa que, após 17 encontros grupais, os participantes apresentaram crescente percepção e clareza acerca das questões institucionais relacionadas à equipe de saúde da família, assim como maior apropriação de seu espaço e papel profissional (Furlan, 2005).

Em uma pesquisa realizada, Dalla Vecchia e Martins (2009) ressaltam ser necessária a existência de um espaço que possibilite a discussão sobre o trabalho comunitário cotidiano e sobre os sentidos pessoais dados pelos profissionais da saúde às ações que executam. Em uma perspectiva similar, Camargo-Borges e Cardoso (2005) destacam a necessidade de se criar ferramentas de intervenção mais apropriadas para o trabalho na saúde pública, sugerindo que a inserção da Psicologia na Saúde da Família pode trazer grandes contribuições.

Segundo os autores acima citados, atualmente, a Psicologia tem despontado na Saúde da Família através de duas intervenções principais: o trabalho com grupos na comunidade e a capacitação e assessoria em saúde mental às equipes. Os autores, porém, provocam os leitores a ampliar o espectro de ações desenvolvidas pela Psicologia através da produção continuada de conhecimentos na área e da criação de novas propostas, utilizando-se dos saberes próprios desse campo para potencializar o pressuposto de práticas mais relacionais sobre o qual se pautam as diretrizes do SUS (Camargo-Borges \& Cardoso, 2005).

O trabalho aqui apresentado vai ao encontro da proposição lançada por Camargo-Borges e Cardoso e das demais experiências relatadas, visando a possibilitar um espaço de construção de saberes por ambas as partes: tanto pelas agentes de saúde participantes quanto pelas coordenadoras do projeto; assim, pretende relatar os resultados dessa natureza de intervenção a partir das especificidades do contexto em que as participantes vivem, bem como das particularidades do grupo.

\section{Método}

Foram realizados encontros grupais quinzenais com as 15 agentes comunitárias, em uma sala de reuniões da unidade básica de saúde. Os grupos foram de reflexão, assim caracterizados por se orientarem, através da reflexão e da indagação, para a resolução das ansiedades e tensões originadas na prática profissional dos participantes (Coronel, 1997).

Nos encontros, foram propostas técnicas de grupo previamente planejadas pelas coordenadoras, destinadas a sensibilizar e a provocar a reflexão e a construção de soluções para as problemáticas identificadas pelas participantes. As propostas apresentadas ao grupo foram estratégias estabelecidas visando a um objetivo definido, porém flexíveis às modificações que podem ocorrer nas pessoas a partir de suas interações (Morin, 2003).

Além dos encontros com as agentes de saúde, as orientadoras e a bolsista reuniramse semanalmente para avaliar os encontros realizados, discutir referenciais teóricos pertinentes e planejar as próximas atividades a serem desenvolvidas, a partir das necessidades identificadas no grupo. 


\section{Resultados}

No período compreendido entre agosto de 2008 e julho de 2009, foram efetuados 18 encontros quinzenais com as agentes de saúde, e, no decorrer desse período, o grupo passou por um processo de transformação de suas demandas.

No início das atividades, as experiências grupais revelaram que as participantes estavam vivenciando dificuldades de relacionamento interpessoal no grupo e de comunicação com outros profissionais das equipes de ESF. Tais dificuldades estavam relacionadas a um sentimento de não pertencimento às equipes de ESF e ao quadro de funcionários da UBS, o que gerava reflexos no sentimento de pertença ao seu próprio grupo de agentes de saúde.

Nesse contexto, os objetivos estabelecidos para os primeiros encontros foram explorar a relação das agentes de saúde entre si e com as equipes e fomentar a reflexão sobre a responsabilidade que cada uma delas possui em seus relacionamentos. Para tanto, foram realizadas atividades como a montagem de uma linha do tempo, a identificação das expectativas sobre o projeto e a reflexão sobre a responsabilidade de cada uma frente a seus relacionamentos.

As reflexões decorrentes dessas atividades resultaram em maior apropriação, por parte das participantes, de seus sentimentos e em uma crescente tomada de responsabilidade por suas atitudes. Isso ficou evidente no próprio comportamento das agentes durante os encontros, que demonstraram maior respeito, interesse, companheirismo e capacidade de escuta mútua, bem como menor quantidade de queixas relacionadas aos outros profissionais.

Ao mesmo tempo em que essas mudanças foram acontecendo, o foco do grupo passou a se direcionar para assuntos referentes

à prática cotidiana das participantes, incluindo temáticas como a delimitação do espaço, limites, características e funções das profissionais e o seu relacionamento com a comunidade. O planejamento dos encontros passou a ter como foco a análise das atribuições e nuances do trabalho das agentes comunitárias, visando a explorar as dificuldades encontradas pelas profissionais em sua prática cotidiana e a refletir sobre o modo como manejam tais situações.

Entre as problemáticas discutidas, estão casos de violência doméstica, alcoolismo, abuso de drogas, transtorno depressivo e psicoses, temas que foram trabalhados através de dinâmicas grupais que serviram para fomentar a reflexão e possibilitar a construção conjunta de possibilidades de manejo das situações. Além disso, o trabalho nesse momento do processo grupal incluiu importantes discussões sobre a identidade das agentes comunitárias e as delimitações feitas por elas entre seus papéis de profissionais da saúde e de moradoras do bairro.

Essa última questão já permeava implicitamente grande parte dos encontros, pois muitas vezes as participantes se identificavam com certos problemas dos cadastrados ou se reportavam a casos das próprias famílias. Percebe-se que isso ocorre devido às vinculações prévias das agentes com a comunidade, e também porque o ambiente no qual os usuários da UBS vivem é o mesmo que influencia a sua vida pessoal e familiar.

Com base nesse contexto, o objetivo planejado para o trabalho incluiu abrir um espaço de continência que pudesse funcionar como via de expressão e de elaboração das dificuldades, visando a minimizar a confusão decorrente do fato de serem moradoras da comunidade e de nela trabalharem e a propiciar uma apropriação mais realista das suas responsabilidades, papéis e atribuições. 
Nesse momento, percebemos ser adequada para o trabalho no grupo a proposição de uma atividade que contemplasse a reflexão sobre as características particulares que cada agente de saúde possui e que facilitam ou dificultam a sua prática profissional.

No dia em que essa atividade seria proposta, porém, o grupo iniciou o encontro conversando sobre outra temática pertinente à sua prática de trabalho, que envolvia, ao invés da discussão sobre as características pessoais de cada participante, as características próprias do grupo para lidar com as adversidades que enfrentava. A partir desse comportamento das participantes, no qual elas próprias decidiram o tema do encontro, as coordenadoras decidiram utilizar como estratégia para os próximos encontros a não proposição de tarefas e a escuta do conteúdo emergente, com o objetivo tanto de ampliar a percepção das agentes de saúde quanto o seu papel de sujeitos ativos e determinantes do processo grupal.

No primeiro dia em que essa proposta foi utilizada, apenas no final do encontro as agentes de saúde perceberam que nenhuma proposta havia sido feita, momento no qual foram comunicadas de que, a partir de então, seriam elas as responsáveis por escolher a temática da discussão. No encontro seguinte, elas apresentaram uma dificuldade inicial para delimitar um assunto e iniciar a discussão, mas no subsequente, por sua vez, organizaram-se com facilidade para pensar sobre os acontecimentos recentes que lhes eram significativos, decidindo conjuntamente o tema da reunião.

Nesses encontros, um dos assuntos bastante presente foi a relação que as participantes mantêm com os outros profissionais da rede de saúde. O relacionamento com as enfermeiras foi o mais debatido, por ser o que apresenta maior influência na realização de seu trabalho, já que são essas profissionais as que mais as orientam e lhes dão suporte nas ações que realizam.

Essa discussão sobre a relação das agentes de saúde com as enfermeiras se intensificou nos últimos meses do projeto, devido à troca de enfermeiras que estava ocorrendo nas três equipes de ESF. Tal mudança estava sendo vivenciada pelo grupo com um forte sentimento de ansiedade, advindo das expectativas criadas sobre as características da futura chefe e as possíveis repercussões dessa troca em seu cotidiano profissional. Nessa situação, o trabalho buscou fomentar a discussão sobre essas expectativas, com o objetivo de clarificar os comportamentos que as participantes manifestavam frente à troca de enfermeiras bem como de reforçar as características do grupo que facilitavam a aceitação das mudanças e de atenuar aquelas que dificultavam essa aceitação.

Esse foi o último encontro temático-reflexivo dessa edição do projeto, e, nas semanas posteriores, foram iniciadas as avaliações das atividades, que foram realizadas individualmente com as três enfermeiras das equipes através de entrevistas préestruturadas. Com as agentes de saúde, foi realizada uma avaliação escrita individual no último encontro, após a qual as percepções das participantes foram debatidas conjuntamente no grupo.

Na perspectiva das enfermeiras, após o início do projeto de extensão em agosto de 2008, as agentes de saúde passaram a agir de forma mais ética, centrada e colaborativa, com diminuição das resistências que apresentavam em relação a algumas propostas e cobranças burocráticas. Da mesma forma, essas profissionais perceberam o estabelecimento de um melhor relacionamento entre as participantes, com a diminuição de situações de intrigas e maior capacidade para suportar e apoiar as dificuldades das colegas. As 
enfermeiras comentaram que a eficiência das atividades realizadas pelas agentes de saúde depende muito das características individuais de cada uma, também tendo influência nisso os fatores tempo de trabalho e experiência adquirida.

A avaliação com as agentes de saúde apontou percepções que corroboram os aspectos salientados pelas enfermeiras, ao mesmo tempo em que confirmam as observações feitas pelas coordenadoras do grupo ao longo do processo. As participantes assinalaram ter havido melhora no relacionamento, tanto entre si quanto com as enfermeiras, o que influenciou na motivação para trabalhar. Elas relataram ter percebido o quanto as pessoas são diferentes e veem as coisas de formas distintas, e o quanto as atitudes que tomam influenciam na manutenção de suas relações.

Ainda segundo as participantes, as atividades Ihes possibilitaram conhecer-se melhor, olhar para si mesmas e refletir sobre como podem melhorar no dia a dia. Elas relataram ter percebido o espaço do projeto como um lugar de apoio, onde encontraram escuta e força e construíram alternativas para lidar com certas situações. De acordo com elas, isso gerou reflexos significativos em sua prática com a comunidade, tais como maior segurança e confiança para realizar o trabalho, valorização pessoal e de sua prática profissional, maior facilidade em perceber a visão dos outros e compreender a importância da escuta na relação com os usuários.

Quando questionadas sobre as sugestões de tarefas e temas que gostariam de explorar na próxima edição do projeto, as participantes solicitaram a manutenção do espaço no formato atual, com mais tempo para o trabalho e associado a atividades que viabilizem maior conhecimento técnicocientífico para subsidiar a prática cotidiana. $\mathrm{Na}$ percepção das enfermeiras, o projeto pode auxiliar as agentes de saúde no que diz respeito à diminuição da ansiedade e euforia em relação à resolutividade dos problemas da população, trabalhando questões acerca dos limites de atuação, da reafirmação de suas funções e do relacionamento com a comunidade.

\section{Discussão dos resultados}

O trabalho desenvolvido com as agentes comunitárias de saúde ao longo deste ano abre portas para diversas reflexões concernentes à prática dessas trabalhadoras na saúde coletiva. Desde conhecimentos técnicos e científicos até relacionamentos interpessoais, percebe-se que vários fatores influenciam no trabalho dessas profissionais, muitas vezes requerendo suporte.

Frente a essa diversidade de fatores, constatase que as atividades realizadas através desse projeto de extensão são importantes ferramentas de apoio ao trabalho dos agentes de saúde. Assim, a discussão dos resultados será feita com base em quatro linhas temáticas que permearam o processo grupal realizado, como ilustra a Tabela 01. 
Tabela 1 - Linhas temáticas de discussão do processo grupal

\begin{tabular}{|c|c|c|}
\hline Situações prévias & Estratégias e objetivos & Resultados visualizados \\
\hline $\begin{array}{l}\text { Conflitos na relação } \\
\text { entre as participantes }\end{array}$ & $\begin{array}{l}\text { Análise das atitudes e } \\
\text { comportamentos; } \\
\text { reconstrução histórica de seu } \\
\text { trabalho e relações; } \\
\text { apropriação de sentimentos; }\end{array}$ & $\begin{array}{l}\text { Melhora no relacionamento; } \\
\text { compreensão das diferenças } \\
\text { entre as pessoas; } \\
\text { responsabilização pelas } \\
\text { próprias atitudes; } \\
\text { maior capacidade de apoio e } \\
\text { suporte umas às outras; } \\
\text { percepção de seu grupo de } \\
\text { agentes comunitárias como } \\
\text { uma equipe; }\end{array}$ \\
\hline $\begin{array}{l}\text { Altas expectativas de } \\
\text { atuação; } \\
\text { limitações na } \\
\text { resolutividade } \\
\text { dos problemas da } \\
\text { comunidade; } \\
\text { desvalorização } \\
\text { profissional }\end{array}$ & $\begin{array}{l}\text { Discussão de casos e análise } \\
\text { das possibilidades de } \\
\text { atuação; } \\
\text { reflexão sobre as atribuições } \\
\text { e limitações profissionais; }\end{array}$ & $\begin{array}{l}\text { Maior segurança, confiança e } \\
\text { valorização; } \\
\text { reconhecimento da } \\
\text { importância da escuta; } \\
\text { maior facilidade em perceber a } \\
\text { visão dos outros; }\end{array}$ \\
\hline
\end{tabular}

Dificuldades na

relação com as enfermeiras e outros integrantes das equipes de saúde

\section{Características} pessoais e tempo de trabalho relacionados à qualidade do atendimento
Discussão sobre os diferentes papéis profissionais; análise de preconceitos e desmistificação de fantasias Estratégias de comunicação
Melhora no relacionamento; participantes menos resistentes e mais colaborativas
Maior autoconhecimento; possibilidade de refletir sobre como melhorar no dia a dia; percepção de possibilidades alternativas para lidar com certas situações

\begin{tabular}{ll} 
Compartilhamento de & Maior autoconhecimento; \\
experiências; & possibilidade de refletir sobre \\
construção conjunta de & como melhorar no dia a dia; \\
soluções para os problemas; & percepção de possibilidades \\
reflexões sobre características & $\begin{array}{l}\text { alternativas para lidar com } \\
\text { individuais }\end{array}$ \\
\hline
\end{tabular}

Fonte: Dados da pesquisa

A primeira situação trabalhada com as agentes de saúde, relacionada à presença de conflitos na relação das participantes, foi fundamental para o trabalho do grupo no projeto de extensão, e considera-se esse um fator que merece atenção em qualquer contexto do trabalho em saúde. No que diz respeito às agentes comunitárias, isso se configura porque a construção de soluções para as problemáticas identificadas em sua prática requer o compartilhamento de experiências, o que exige cooperação e sensibilidade para os relatos das colegas.

Nessa situação, percebe-se que a compreensão das agentes de saúde sobre o modo como agem em seus relacionamentos pode exercer grande influência na interação com a comunidade, pois o autoconhecimento daí advindo permite aprimorar os recursos relacionais que possuem para executar as ações em saúde, o que vai ao encontro dos pressupostos sobre os quais está pautado o trabalho dos agentes comunitários na atenção básica, em que se considera essencial o estabelecimento de vínculos com os usuários (Brasil, 2007; Lima \& Cockell, 2009). 
Sob tais circunstâncias, entende-se que os resultados descritos na Tabela 01, de compreensão das diferenças entre as pessoas, responsabilização pelas próprias atitudes, maior capacidade de apoio e suporte e percepção de si mesmas como uma equipe são importantes atributos para o acolhimento das necessidades da comunidade, pois o trabalho das agentes de saúde na identificação das problemáticas e vulnerabilidades dos usuários exige um olhar atento para as necessidades que estes demandam.

De acordo com isso, pensa-se que, no momento em que as agentes de saúde conseguem se perceber como capazes de dar apoio às necessidades das colegas, elas também se sentirão mais seguras na função de dar escuta, acolhimento e suporte aos problemas que a comunidade Ihes remete. Além disso, o fato de saberem que terão suporte nas colegas torna-se fator motivacional para a realização de seu trabalho, pois sabem que terão um espaço para a expressão e a elaboração das dificuldades que enfrentam. O que foi dito acima vai ao encontro dos apontamentos de Dalla Vechia e Martins (2009), que destacam a importância de abrir espaços de discussão sobre o trabalho comunitário cotidiano e sobre os significados dados pelos profissionais às ações que executam.

Tomando esses resultados como base para o trabalho que se seguiu, a segunda linha de trabalho que se configurou no processo grupal abarcou a discussão sobre as expectativas de atuação profissional, as limitações na resolutividade dos problemas da comunidade e a desvalorização profissional sentida pelas agentes de saúde. Estudos apontam que o profissional agente de saúde frequentemente possui o sentimento de que é responsável pela resolução dos problemas da comunidade, sentimento associado ao papel social de agente de mudanças que lhe foi atribuído e à sua característica de ser tanto membro da comunidade quanto trabalhador a seu serviço (Lima \& Cockell, 2009; Martines \& Chaves, 2007; Nunes et. al., 2002).

Sob tais condições, as frustrações decorrentes da percepção de seus limites de atuação acabam por se configurar como fator de desvalorização desses profissionais, que, além de cobrarem a si mesmos pelo seu desempenho, recebem e se tornam depósito das cobranças da comunidade. Nesse sentido, pensa-se que discussões fundamentadas em casos do cotidiano dos agentes de saúde podem Ihes permitir visualizar, em uma perspectiva mais realista, as suas possibilidades e os seus limites para atuar em cada situação.

No contexto desse projeto de extensão, percebeu-se que o debate sobre as possibilidades e os limites de atuação permitiu às participantes valorizar os recursos próprios que possuem, tal como a escuta, que foi reconhecida por elas como um elemento potencialmente terapêutico aos cadastrados. Furlan (2005) afirma que as tarefas dos agentes de saúde deveriam ser expandidas para além da função de identificar problemas e de encaminhá-los para outros profissionais, e propõe que esses trabalhadores sejam capacitados para exercer outros tipos de ações que aprimorem a efetividade de suas tarefas.

Sabe-se, entretanto, que a capacitação dos agentes de saúde para executar ações diferenciadas esbarra nas questões institucionais de seu trabalho, que são alvo de inúmeras críticas e discussões, relacionadas, entre outras coisas, a situações de saber e poder entre as profissões (Bachili, et. al., 2008; Fortes \& Spinetti, 2004). Nessas circunstâncias, pensa-se que, mesmo havendo essas limitações, o próprio trabalho de escuta e apoio que os agentes de saúde executam já se caracteriza como um elemento terapêutico para as pessoas que estão em sofrimento, e que a capacitação dessas habilidades relacionais pode ser utilizada como uma 
estratégia incipiente para qualificar o trabalho desses profissionais.

No que diz respeito à terceira linha de discussão proposta na Tabela 01, dificuldades na relação com as enfermeiras e com outros profissionais, pode-se observar que as agentes de saúde já faziam referências a esse assunto desde o início das atividades, em agosto de 2009, conforme relatado nos resultados deste artigo. Apesar disso, nota-se que a reflexão sobre o relacionamento estabelecido com as enfermeiras adquiriu consistência apenas a partir do momento em que as participantes estavam mais apropriadas de suas próprias características, atribuições e limitações.

Sob tais circunstâncias, a discussão sobre as diferenças entre os papéis de ambas as profissões, a análise acerca dos pré-conceitos e fantasias das participantes e a exploração de estratégias de comunicação nas situações de conflito foram dispositivos que possibilitaram ampliar a compreensão das participantes acerca dos fatores envolvidos nesses relacionamentos. Furlan (2005) corrobora a existência dessa possibilidade no trabalho dos agentes de saúde ao salientar que, após um trabalho de capacitação dos profissionais, estes apresentaram maior clareza acerca das questões institucionais relacionadas à equipe, assim como maior apropriação de seu espaço e papel profissional.

Por fim, para configurar a quarta linha de discussão proposta na Tabela 01, considerase a relação das características individuais de cada agente de saúde como um fator de grande influência na realização do atendimento à comunidade. Entende-se que atividades grupais de reflexão possibilitam a profissionais de saúde olhar para si mesmos e refletir sobre suas forças e fraquezas no trabalho comunitário. Nesse projeto, os relatos das agentes de saúde na avaliação corroboraram essa possibilidade, visto que elas mesmas apontaram ter tido a oportunidade de se conhecer melhor e de refletir sobre as formas de melhorar no dia a dia.

Nessa mesma perspectiva, considerando a exposição das enfermeiras, que ressaltou os fatores tempo e experiência como relacionados ao bom desempenho das agentes de saúde, pensa-se que a troca de conhecimentos e a discussão sobre situações vivenciadas na prática cotidiana permitem às profissionais que ainda não vivenciaram determinados tipos de ocorrência anteciparem a reflexão sobre estas. Isso se configura como uma forma de capacitação, que habilita as agentes de saúde a, posteriormente, desenvolverem seu trabalho com maiores referências e segurança, permitindo-lhes pensar em ações alternativas para manejar as situações inusitadas.

\section{Considerações finais}

O trabalho realizado por meio desse projeto de extensão revela que o objetivo proposto, de abrir espaços de reflexão sobre o cotidiano de trabalho dos profissionais da saúde coletiva e possibilitar a construção conjunta de saberes sobre a sua prática, configura-se como importante atividade no trabalho em saúde pública.

Os resultados denotam um grande aperfeiçoamento pessoal, profissional e grupal das participantes do projeto, que relataram transpor as reflexões efetuadas no grupo para os desafios de seu dia a dia. Percebe-se que o espaço de escuta e reflexão que lhes foi disponibilizado favoreceu maior apropriação acerca de seu papel comunitário de trabalhadoras da saúde, permitindo reflexão sobre as suas possibilidades e limites de ação.

Apesar de os resultados visualizados não serem generalizáveis por estarem vinculados a um grupo específico de trabalhadores, entendese que a abertura de espaços de reflexão, que possibilitem aos diferentes profissionais da saúde a expressão e a discussão sobre as 
dificuldades encontradas em sua prática, pode representar um potencializador das ações em saúde.

Pensa-se que o trabalho realizado demonstra a possibilidade de se reforçar o trabalho dos agentes comunitários de saúde através do investimento em seus recursos pessoais e de relacionamento, assim como na construção de um sentido de equipe profissional. Um contraponto observado pelas coordenadoras, porém, questiona os limites entre aquilo que é pertinente ao trabalho com as agentes de saúde, como os sentidos dados a essa profissão, e aquilo que pertence a toda a equipe de Saúde da Família.
Acredita-se que o trabalho realizado esbarra em limites institucionais referentes à organização do serviço de saúde, e que não cabe à Psicologia tentar, isoladamente, suprir as diversas demandas trazidas pelas agentes comunitárias. Entende-se que projetos dessa natureza podem ser aprimorados se articularem os diferentes profissionais das equipes de saúde, primando pela troca de experiências interdisciplinares, pela efetivação do trabalho interdisciplinar e pela construção conjunta de conhecimentos sobre a realidade com a qual a equipe trabalha. 


\section{Angélica Paula Neumann}

Acadêmica do $10^{\circ}$ semestre do curso de Graduação em Psicologia da Universidade Regional Integrada do Alto Uruguai e das Missões - Campus de Erechim. Ex-bolsista do Projeto de Extensão Universitária "A equipe de saúde na comunidade", Rio Grande do Sul, RS - Brasil.

E-mail: angelicaneumann@gmail.com

\section{Cassandra Cardoso}

Mestre em Psicologia Clínica pela Pontifícia Universidade Católica do Rio Grande do Sul. Professora titular do Curso de Psicologia da Universidade Regional Integrada do Alto Uruguai e das Missões, Rio Grande do Sul, RS - Brasil. E-mail: cassandra@uricer.edu.br

\section{Silvana de Oliveira}

Mestre em Psicologia Social e Institucional pela Universidade Federal do Rio Grande do Sul. Atualmente trabalha no CRAS do município de Osório, é docente convidada em pós-graduação. É psicoterapeuta, Rio Grande do Sul, RS - Brasil.

E-mail: silvana_deoliveira@hotmail.com

\section{Endereço para envio de correspondência:}

Rua Fernando Sefrin, no125, Bairro Fátima, Erechim, Rio Grande do Sul - Brasil. CEP: 99700-000

Recebido 7/5/2010, 1a Reformulação 5/7/2011, Aprovado 12/8/2011.

\section{Referências}

Bachilli, R. G., Scavassa, A. J., Spiri, W. C. (2008). A identidade do agente comunitário de saúde: uma abordagem fenomenológica. Ciência \& Saúde Coletiva, 13(1), 51-60.

Brasil. Ministério da saúde. Secretaria de Atenção à Saúde. Departamento de Atenção Básica. (2007). Política Nacional de Atenção Básica (4a. ed.). Braśilia, DF: Ministério da Saúde.

Camargo-Borges, C., Cardoso, C. L. (2005). A psicologia e a estratégia saúde da família: compondo saberes e fazeres. Psicologia \& Sociedade, 17(2). Recuperado em 10 julho 2009, de http://www.scielo.br/scielo/.

Coronel, L. C. I. (1997). Grupos de reflexão. In D. E. Zimerman, Como trabalhamos com grupos (pp. 345-349). Porto Alegre: Artes Médicas.

Dalla Vecchia, M., Martins, S. T. F. (2009). Concepções dos cuidados em saúde por uma equipe de saúde da família, em perspectiva histórico-cultural. Ciência e Saúde Coletiva, 14(1), 183-193.

Fernandes, J. C. L. (1992). Agentes de saúde em comunidades urbanas. Cadernos de Saúde Pública, 8(2), Recuperado em 05 março 2009, de http://www.scielo.br/scielo/.

Fortes, P. A. C., Spinetti, S. R. (2004). A informação nas relações entre os agentes comunitários de saúde e os usuários do Programa de Saúde da Família. Saúde e Sociedade, 13(2). Recuperado em 2 agosto 2008, de http://www.scielo.br/ scielo/.
Furlan, P. G. (2005). Intervenção "paidéia" com agentes comunitários de saúde: estratégia de educação permanente e apoio institucional no contexto das políticas públicas. Trabalho de conclusão de curso, UNICAMP, Campinas, SP. Recuperado em 19 maio 2009, do website da Faculdade Ciências Médicas da Universidade Estadual de Campinas (UNICAMP):http://www.fcm.unicamp.br/laboratorios/ saude_mental/artigos/tcc/intervencao.pdf.

Lima, J. C., Cockell, F. F. (2009). As novas institucionalidades do trabalho no setor público: os agentes comunitários de saúde. Trabalho, Educação e Saúde, 6(3). Recuperado em 10 julho 2009, da BVS-EPS (Biblioteca Virtual em Saúde - Educação Profissional em Saúde): http://www.bvseps.epsjv.fiocruz.br/.

Martines, W. R. V., Chaves, E. C. (2007). Vulnerabilidade e sofrimento no trabalho do agente comunitário de saúde no Programa de Saúde da Família. Revista da Escola de Enfermagem da USP, 41(3), 426-433.

Morin, E. (2003). A cabeça bem-feita: repensar a reforma, reformar o pensamento (8a ed.). Rio de Janeiro: Bertrand Brasil.

Nunes, M. de O., Trad, L. B., Almeida, B. A., Homem, C. R., Melo, M. C. I. de C. (2002). O agente comunitário de saúde: construção da identidade desse personagem híbrido e polifônico. Cadernos de Saúde Pública, 18(6), 1639-1646. 